\title{
The effect of claw size and wave rate on female choice in a fiddler crab
}

\author{
Sophia Callander • Michael D. Jennions • \\ Patricia R. Y. Backwell
}

Received: 5 July 2011/ Accepted: 13 October 2011/Published online: 3 November 2011

(C) Japan Ethological Society and Springer 2011

\begin{abstract}
How do females select a mate when they have mating preferences for multiple male traits? In experimental studies, female fiddler crabs (Uca mjoebergi) show a strong preference for males with larger claws and higher wave rates. In the field, there is no correlation between male claw size and observed wave rate. Here we document natural mating behaviour and show that females approach males who wave at a higher rate than nearby competitors. On average, an approached male had a significantly larger claw than his two nearest neighbours but did not differ in size from his two closest waving competitors. In general, smaller males were less likely to wave at approaching females. Females therefore approached mates based directly on wave rate but, because smaller males were less likely to wave, this indirectly resulted in female choice for larger than average males. Our study raises two issues. First, how do we relate the field results to previous experimental studies showing a female preference for larger claws? Second, in U. mjoebergi, males defend smaller neighbours against intruders. Our study suggests that one benefit of such defence coalitions is to decrease the number of immediate competitors present during female mate choice by retaining smaller neighbours.
\end{abstract}

Keywords Multiple traits - Female choice - Coalitions . Fiddler crab $\cdot$ Sexual selection

S. Callander $(\varangle) \cdot$ M. D. Jennions · P. R. Y. Backwell Evolution, Ecology and Genetics, Research School of Biology, The Australian National University, Building 116, Daley Rd, Canberra, ACT 0200, Australia

e-mail: sophia.callander@anu.edu.au

\section{Introduction}

Male sexual displays are often complex and involve the use of multiple signals (review: Candolin 2003). For example, female choice in birds has been shown to act on at least three different male traits in a single species: plumage ornamentation, courtship display and advertisement song (e.g. Borgia 1985; Marchettii 1998; Patricelli et al. 2003; Coleman et al. 2004; Loyau et al. 2005; Patricelli et al. 2006). Selection on male secondary sexual characteristics is often strongly driven by female mating preferences (Andersson 1994; Candolin 2003). The evolution of multiple male sexual signals might have been favoured by selection for improved signal detection and/or facilitate more accurate discrimination of quality among males by choosy females. For instance, background body coloration can amplify the conspicuousness of a primary colour signal by increasing the degree of visual contrast (Brooks 1996). Similarly, females might assess multiple cues to obtain several partially independent estimates of male quality. This might allow females to more quickly assess variation among males or, by averaging across the different indices, reduce measurement/assessment error to obtain a more accurate estimate of a male's underlying quality (Candolin 2003). Surprisingly, however, the expression of different male sexual traits is often found to be uncorrelated (Zuk et al. 1990; Birkhead et al. 1998; Marchettii 1998; Kraak et al. 1999; Badyaev et al. 2001; Madsen et al. 2007). If this is the case, how do females choose mates when they pay attention to two or more different sexually selected male traits?

The fiddler crab Uca mjoebergi offers an ideal study system to examine the relative importance of multiple male sexual signals in a natural setting. Mate-searching females move through the population seeking out a mate. 
Neighbouring males tend to form small groups of approximately 2-6 males around these females. Males have a greatly enlarged major claw, which they wave to attract a female's attention. Previous experimental studies using robotic crabs have shown that females prefer to approach both males with larger claws (Reaney 2009; Milner et al. 2010) and males who wave at a faster rate (when male traits are manipulated independently; Reaney et al. 2008; Reaney 2009). In a two-choice experiment where a pair of robotic test males differed in attractiveness depending on which trait was considered (i.e. one of the males had a larger claw but a slower wave rate than the other male), females did not show a preference for either male (Reaney 2009). Under natural conditions, however, females have been observed to more often approach males with claws that are larger than average, even though there is no apparent phenotypic correlation between male claw size and wave rate among waving males (Reaney and Backwell 2007). To date, no study has examined the effect of both claw size and wave rate on female choice in $U$. mjoebergi in a natural setting.

Here we test whether females base their mate choice decisions on wave rate and/or claw size under natural conditions by comparing chosen males with their immediate neighbours. Trait differences between chosen males and neighbours are usually attributed to female choice. We found, however, that some males did not wave at matesearching females so they were not part of the immediate set of potential mates. This could generate non-random mating patterns that are not directly dependent on female choice. In addition, female choice might also be directly affected whenever the composition of the set of potential mates differs from that in the wider population. We therefore measured the claw size and wave rate of: (1) the two nearest male neighbours of the chosen male irrespective of whether or not they waved; and (2) the two closest male competitors that were waving when the female made her mate choice decision. In some cases, the same male(s) fell into both categories (i.e. whenever one or both of the two nearest neighbours waved).

\section{Materials and methods}

\section{Study system}

The fiddler crab $U$. mjoebergi inhabits dense, mix-sexed, intertidal colonies. Both sexes hold territories consisting of a burrow surrounded by a 10- to 20-cm-diameter area of surface sediment on which they feed. Territories are immediately adjacent to each other with shared borders. Prior to mating, most females leave their own territory and move through the population in search of a mate. Males court females by waving their major claw. Courting males tend to surround the female and orientate towards her, which creates a small cluster of waving males. Males mainly compete with their immediate territorial neighbours, but some waving males travel from a more distant territory to court a female (Callander et al. 2011). Female choice is a two-step process in most burrow-mating fiddler crabs. First, females select which males to visit based on male claw size, wave rate and display synchrony (Reaney and Backwell 2007). Second, a female then visits the chosen male and briefly enters his burrow. The decision to stay and mate, or to leave and continue mate-searching, is based on burrow quality. Most females will sequentially visit several males (deRivera 2005) before eventually entering a burrow that they deem suitable for breeding (Reaney and Backwell 2007). Once they do so, mating occurs inside the burrow. A higher female visitation rate therefore increases a male's likelihood of mating success. We examined the behaviour of U. mjoebergi at East Point Reserve in Darwin, Australia, in October-December 2009. Work was conducted each biweekly, semi-lunar cycle during the approximately 5-day-long mating period centred on the neap tide.

\section{Natural observations}

Females were initially identified as mate-searching if we saw them visit at least one courting male. We defined a visit if a female directly approached a courting male and touched his burrow entrance with her legs (deRivera 2005). We then tracked mate-searching females until they next visited a male. Afterwards, we caught and measured the female, the visited (hereafter referred to as 'chosen') male and his two nearest male neighbours, who always held territories abutting that of the chosen male. If one or neither of these neighbours waved when the female's approached the chosen male, we also caught the next closest male(s) until we had captured the two closest waving males. In each case, only the two closest males were caught due to logistical constraints. For each female the number of males we needed to capture therefore ranged between two and four. In a few cases, we were unable to catch all the requisite males so the final sample sizes differed slightly among male types (see "Results"). In total, we successfully obtained data from 21 mate-searching females. We measured the carapace width of both sexes and the major claw length of males to the nearest $0.1 \mathrm{~mm}$ (carapace size of females $8.8 \pm 1.0 \mathrm{~mm}$ and males $10.4 \pm 1.3 \mathrm{~mm}$, both mean $\pm \mathrm{SD}$ ). As male claw length and body size (carapace width) were tightly correlated ( $r=0.903)$, we only present the results of analysis using claw size. We also videorecorded the mate-searching female to determine the wave rate (waves/minute) of the chosen and neighbouring males. We defined the mate choice event as occurring 'from the 
time when males in the cluster commenced waving until the last full wave of the chosen male'. Once a female has selected a male, his wave rate can accelerate because he produces quick half waves as she moves closer to him. These were excluded from our definition of the mate choice event. We made observations haphazardly over a large area of mudflat $\left(>1,000 \mathrm{~m}^{2}\right)$. After each visit, we relocated to another part of the mudflat to avoid using the same males twice. We also marked each female prior to release so that no female was used more than once.

\section{Statistical analysis}

We used paired $t$ tests (matched by female visit) to investigate whether the claw size and wave rate of chosen males differed from that of (1) each of his two closest male neighbours, and (2) each of the two closest waving males. These tests were one-tailed given the a priori prediction that females prefer males with larger claws (Reaney 2009; Milner et al. 2010), and higher wave rates (Reaney et al. 2008; Reaney 2009). For the comparison of size between waving and non-waving males, we pooled the data and used independent sample $t$ tests (two-tailed).

We also used univariate linear mixed models to test whether wave rate differed between chosen and non-chosen males while controlling for claw size (fixed factors: whether the male was chosen and male claw size; random factor: courtship group identity). We conducted a comparable test for any difference in claw size, while controlling for wave rate. For both models, we initially included the interaction between the fixed terms, but removed it from the final model as it was non-significant (Crawley 2002). Claw size and wave rate were log-transformed to meet assumptions of normality. All statistical tests were performed using SPSS 19.0 with $\alpha=0.05$. All summary statistics are presented as mean $\pm \mathrm{SD}$.

\section{Results}

Claw size of visited males compared to their neighbours

On average, the chosen male had a claw that was significantly larger than that of either of the two nearest male neighbours (chosen male $16.4 \pm 2.6 \mathrm{~mm}$; closest neighbour $14.7 \pm 3.6 \mathrm{~mm}, t=2.13, p=0.02$; second closest neighbour $14.1 \pm 2.9 \mathrm{~mm}, \quad t=2.76, \quad p=0.01 ; \quad$ all $n=21$ ). However, the claw length of the chosen male did not differ from that of the two nearest males that waved (closest 15.6 $\pm 3.4 \mathrm{~mm}, t=0.84, p=0.22, n=19$; second closest $15.5 \pm 3.0 \mathrm{~mm}, t=0.99, p=0.17, n=20$ ). After pooling the data, we found that waving males were significantly larger than non-waving males (waving
$15.8 \pm 3.0 \mathrm{~mm}, \quad n=62 ; \quad$ non-waving $13.4 \pm 4.0 \mathrm{~mm}$, $n=7 ; t=2.00, p=0.049)$. On average, there was an $18.4 \%$ likelihood that a chosen male's closest or second closest neighbour did not wave during the female's approach $(n=7$ of 38$)$. The mean claw size of visited males $(16.4 \pm 2.6 \mathrm{~mm}, n=21)$ was significantly larger than the average for the study population $(14.9 \pm 4.3 \mathrm{~mm}$, $n=222$; see Milner et al. 2011; $t=2.22, p=0.034$ ).

Wave rate of visited males compared to their neighbours

On average, the chosen males had a significantly higher wave rate $(33.6 \pm 17.0$ waves $/ \mathrm{min})$ than either his closest competitor $(29.1 \pm 13.0$ waves $/ \mathrm{min}, t=2.01, \quad p=0.03$, $n=20)$ or his next closest competitor $(27.9 \pm 13.4$ waves/ $\min , t=2.25, p=0.02, n=20)$. Chosen males still waved faster than non-chosen males $\left(F_{1,31}=7.351, p=0.011\right)$ even after controlling for a non-significant effect of claw size $\left(F_{1,35}=0.993, p=0.326\right)$. The claw size of chosen males did not, however, differ from that of non-chosen males $\left(F_{1,47}=1.272, p=0.265\right)$, even after controlling for any effect of wave rate $\left(F_{1,47}=1.694, p=0.199\right)$. There were no significant interactions between male type and wave rate or claw size (both $p>0.30$ ).

\section{Discussion}

A female $U$. mjoebergi selects mates from small clusters of waving males that surround her as she moves slowly through the population. Waving males in a cluster compete with each other to induce a female to visit their burrow. Here we show that chosen males have a significantly higher wave rate than that of their two nearest male neighbours. Chosen males did not, however, have larger claws than their two nearest waving competitors. Under natural conditions, females therefore actively approached males based on wave rate but not claw size. Experimental studies show, however, that when there is no difference in wave rate between males then claw size does affect female mate choice (Reaney 2009; Milner et al. 2010). It is possible that with a sufficiently large sample size we might have detected a size difference between chosen and neighbouring waving males. The fact remains, however, that the detectable effect of wave rate was far greater than that for claw size, so it was a more important criterion for female choice in the current study of natural mating behaviour. Our finding could be attributable to a difference in the weighting females give to male attractiveness based on wave rate compared to claw size. This could be partly due to a difference in the level of variation among potential mates in preferred traits, if females pay more attention to 
traits with greater variability because this makes it easier to discriminate among potential mates (e.g. Kodric-Brown and Nicoletto 2001). Specifically, if variation in male claw size is lower than that in wave rate then it might be easier for females to choose a mate based on wave rate than size. Previous experimental work in $U$. mjobergi found that females lose their preferences for large claws when the size difference between claws in two-choice trials decreased from 3 to $2 \mathrm{~mm}$ (Reaney 2009). But why would claw size become less variable?

The mean probability that the neighbour of a chosen male waved at an approaching female was $81.6 \%$. Courting males therefore do not always compete for females with their immediate neighbours. Chosen males had larger claws than those of immediate male neighbours on abutting territories, while there was no size difference between the chosen male and the two closest waving males. This implies that a smaller clawed male is less likely to wave, and a direct comparison of the mean size of waving and non-waving males confirmed this pattern. This means that waving males in a cluster are more similar in size than males in the general population. So, the smaller effect of claw size on male mating success could be partly due to lower variation in claw size among potential (i.e. waving) mates. Low variability in claw size amongst waving males could result from male-male interactions limiting small males from joining a courtship group. While wave rate seems a more important criteria to female choice, females may passively choose mates based on claw size. It is noteworthy, however, that chosen males still waved faster than non-chosen males, even after controlling for male claw size. In contrast, there was no effect of claw size on female choice after controlling for wave rate.

Our findings are similar to those in several other species where there is no correlation between the expression of different male sexual traits (e.g. Zuk et al. 1990; Birkhead et al. 1998; Marchettii 1998; Kraak et al. 1999; Badyaev et al. 2001; Madsen et al. 2007). We also corroborate previous work on U. mjoebergi (Reaney and Backwell 2007) showing that wave rate and male size are not correlated among males that are waving. The waving displays of male fiddler crabs are known to be condition-dependent (Jennions and Backwell 1998), and females might prefer males with faster wave rates because only higher quality males can cope with the greater energetic costs of sustaining an elevated wave rate (Murai et al. 2009).

In agreement with Reaney and Backwell (2007), we found that the mean claw size of visited males $(16.4 \mathrm{~mm})$ was significantly larger than the average claw size in the study population $(14.9 \mathrm{~mm}$; Milner et al. 2011). This is partly because smaller males are less likely to wave. It is possible that smaller males wave less often than larger males because females have a preference for larger claws.
Males that are relatively smaller than their nearby competitors might be less likely to wave due to their lower attractiveness which decreases the benefit of investing in courtship. For example, a recent experimental study in $U$. mjoebergi found that the female preference for a focal male of fixed claw size and wave rate was weaker when he had neighbours with larger claws and a faster wave rate, than when he had neighbours with a smaller claw size and slower wave rate (Callander et al. 2011).

Finally, the propensity of smaller males to wave less often has other implications. It might help to explain the function of defence coalitions by male fiddler crabs (Backwell and Jennions 2004; Detto et al. 2010). In defence coalitions, males help smaller neighbours to defend their burrow. This decreases the likelihood that the smaller neighbour is evicted. To date, the main proposed benefits to the helper are avoiding the cost of renegotiating boundaries and/or retaining a weaker neighbour who is less likely to encroach onto the helper's territory (Backwell and Jennions 2004; Detto et al. 2010). We suggest that there is a third benefit: smaller males are less likely to wave and thereby compete for females, increasing the likelihood that the helper will be chosen as a mate.

Acknowledgments We thank Tim Maricic and Isobel Booksmythe for their assistance in the field. Our work was supported by an Australian National University PhD Scholarship (S.C.) and the Australian Research Council (P.R.Y.B. and M.D.J.).

\section{References}

Andersson M (1994) Sexual selection. Princeton University Press, Princeton

Backwell PRY, Jennions MD (2004) Coalition among male fiddler crabs. Nature 430:417

Badyaev AV, Hill GE, Dunn PO, Glen JC (2001) Plumage color as a composite trait: developmental and functional integration of sexual ornamentation. Am Nat 158:221-235

Birkhead TR, Fletcher F, Pellatt EJ (1998) Sexual selection in the zebra finch Taeniopygia guttata: condition, sex traits and immune capacity. Behav Ecol Sociobiol 44:79-191

Borgia G (1985) Bower quality, number of decorations, and mating success of male satin bowerbirds (Ptilonorhynchus violaceus): an experimental analysis. Anim Behav 33:266-271

Brooks R (1996) Melanin pigment as a visual signal amplifier in male guppies. Naturwissenschaften 83:39-41

Callander S, Jennions MD, Backwell PRY (2011) Female choice over short and long distances: neighbour effects. Behav Ecol Sociobiol. doi:10.1007/s00265-011-1216-0

Candolin U (2003) The use of multiple cues in mate choice. Biol Rev 78:575-595

Coleman SW, Patricelli GL, Borgia G (2004) Variable female preferences drive complex male displays. Nature 428:742-745

Crawley MJ (2002) Statistical computing. An introduction to data analysis using S-plus. Wiley, West Sussex

deRivera CE (2005) Long searches for male-defended breeding burrows allow female fiddler crabs, Uca crenulata, to release larvae on time. Anim Behav 70:289-297 
Detto T, Jennions MD, Backwell PRY (2010) When and why do territorial coalitions occur? Experimental evidence in a fiddler crab. Am Nat 175:119-125

Jennions MD, Backwell PRY (1998) Variation in courtship rate in the fiddler crab Uca annulipes: is it related to male attractiveness? Behav Ecol 9:605-611

Kodric-Brown A, Nicoletto PF (2001) Female choice in the guppy (Poecilia reticulata): the interaction between male color and display. Behav Ecol Sociobiol 50:346-351

Kraak SBM, Bakker TCM, Mundwiler B (1999) Sexual selection in sticklebacks in the field: correlates of reproductive, mating, and paternal success. Behav Ecol 10:696-706

Loyau A, Saint Jalme M, Sorci G (2005) Intra and intersexual selection for multiple traits in the peacock (Pavo cristatus). Ethology 111:810-820

Madsen V, Dabelsteen T, Osorio D, Osorno JL (2007) Morphology and ornamentation in male magnificent frigatebirds: variation with age, class and mating status. Am Nat 169:S93-S111

Marchettii K (1998) The evolution of multiple male traits in the yellow-browed leaf warbler. Anim Behav 55:361-376

Milner RNC, Detto T, Jennions MD, Backwell PRY (2010) Experimental evidence for a seasonal shift in the strength of a female mating preference. Behav Ecol 21:311-316

Milner RNC, Jennions MD, Backwell PRY (2011) Know thine enemy's neighbor: neighbor size affects floaters' choice of whom to fight. Behav Ecol. doi:10.1093/beheco/arr073
Murai M, Backwell PRY, Jennions MD (2009) The cost of reliable signaling: experimental evidence for predictable variation among males in a cost-benefit trade-off between sexually selected traits. Evolution 63:2363-2371

Patricelli GL, Uy JAC, Borgia G (2003) Multiple male traits interact: attractive bower decorations facilitate attractive behavioural displays in satin bowerbirds. Proc R Soc Lond B 270:2389-2395

Patricelli GL, Coleman SW, Borgia G (2006) Male satin bowerbirds, Ptilonorhynchus violaceus, adjust their display intensity in response to female startling: an experiment with robotic females. Anim Behav 71:49-59

Reaney LT (2009) Female preference for male phenotypic traits in a fiddler crab: do females use absolute or comparative evaluation? Anim Behav 77:139-143

Reaney LT, Backwell PRY (2007) Temporal constraints and female preference for burrow width in the fiddler crab, Uca mjoebergi. Behav Ecol Sociobiol 61:1515-1521

Reaney LT, Sims RA, Sims SWM, Jennions MD, Backwell PRY (2008) Experiments with robots explain synchronized courtship in fiddler crabs. Curr Biol 18:R62-R63

Zuk M, Thornhill R, Ligon JD, Johnson K, Austad S, Ligon SH, Thornhill NW, Costin C (1990) The role of male ornaments and courtship behavior in female mate choice of red jungle fowl. Am Nat 136:459-473 